\title{
ATTEMPTS TO PRODUCE GYNAECOLOGICAL DISEASE IN GRIVET MONKEYS WITH UREAPLASMA UREALYTICUM
}

\author{
B. R. Møller, F. T. Black and E. A. Freundt \\ Institute of Medical Microbiology, Bartholin Building, University of Aarhus, DK-8000 Aarhus C, \\ Denmark
}

\begin{abstract}
SUMmaRY. Attempts were made to infect grivet monkeys with Ureaplasma urealyticum, including strains freshly isolated from patients with infection of the genito-urinary tract, laboratory reference strains and simian strains. The organisms were inoculated directly into the uterine tubes exposed at laparotomy, or through the cervical canal into the uterine cavity before endometrial curettage; but only colonisation, of up to 5 months' duration, was achieved, without evidence of inflammation in the genital tract or elsewhere, and without an antibody response.
\end{abstract}

\section{INTRODUCTION}

The aetiological implication of Ureaplasma urealyticum in genital disorders of man has been debated since the discovery of this group of mycoplasmas. Recently, urethritis has been produced by inoculation of $U$. urealyticum serotype $\mathrm{V}$ into the urethra of male volunteers (Taylor-Robinson, Csonka and Prentice, 1977).

We previously reported the experimental production of salpingitis and parametritis by the inoculation of Mycoplasma hominis (Møller et al., 1978; Møller and Freundt, 1979; Møller, 1980), M. fermentans (Møller et al., 1980) and Chlamydia trachomatis (Ripa et al., 1979; Møller and Mårdh, 1980) into the upper genital tract of female grivet monkeys. The present paper describes attempts to induce salpingitis with $U$. urealyticum.

\section{MATERIALS AND METHODS}

Organisms. The following pools of $U$. urealyticum were prepared for experimental inoculation. Pool a comprised seven uncloned strains isolated in this laboratory from six male patients with non-gonococcal urethritis (Department of Dermatology and Venereology, Marselisborg Hospital, Aarhus); they represented seven of the eight recognised serotypes (Black, 1970, 1974), namely, types I and III-VIII as identified by the indirect immunofluorescence test (Møller, 1979), and were subjected to minimal subculture before inoculation. Pool $b$ consisted of the reference strains for serotypes I-VIII. Pool $c$ comprised two strains identified as serotypes VI and VIII, isolated in this laboratory from the vagina of a grivet monkey; each was cloned three times. Pool d comprised three strains, serotypes III, IV and VII, isolated in this laboratory from the cervix of a patient with acute salpingitis. An additional inoculum consisted of the single reference strain, serotype $\mathrm{V}$.

Each strain was grown in $300 \mathrm{ml}$ of S-medium (Black, 1973) for $12-14 \mathrm{~h}$ at $37^{\circ} \mathrm{C}$, by which time the organisms were in the late log phase of growth, and then pooled to prepare the various inocula. The pooled suspensions were centrifuged at $10000 \mathrm{rpm}$ for $20 \mathrm{~min}$ in a Sorvall RC2b high-speed centrifuge and the pellet resuspended in PBS, $p \mathrm{H} 7 \cdot 2$, to give a 60 -fold reduction of the original pool volume; the final suspensions contained approximately $10^{8}$ colony-forming units/ml. The single-strain, serotype $\mathrm{V}$, inoculum was prepared similarly.

Monkeys. Eight female grivet monkeys, each weighing $1 \cdot 5-2 \cdot 1 \mathrm{~kg}$, were used. After 
importation from East Africa they were caged and quarantined, as previously described (Møller et al., 1978). They were examined and found to be free from infection with $M$. hominis, $M$. fermentans, $M$. primatum and $U$. urealyticum; these and other pre-inoculation tests were performed as described previously (Møller et al., 1978).

Inoculations. Monkeys 1 and 2 were each given an injection of $0.5 \mathrm{ml}$ of $U$. urealyticum pool $a$, directly into the uterine tubes exposed at laparotomy (Møller et al., 1978). By the same method, monkey 3 was inoculated with $0.5 \mathrm{ml}$ of pool b and monkey 4 with $0.5 \mathrm{ml}$ of pool c. In the case of monkeys 5 and 6 , the organisms were injected through the cervical canal into the uterine cavity $(0.5 \mathrm{ml})$ and this was followed by dilatation of the cervix and curettage of the endometrium as described previously (Møller and Freundt, 1979); monkey 5 received the serotype $\mathrm{V}$ reference strain and monkey 6 received pool $d$. Monkeys 7 and 8 were used as controls and only $0.5 \mathrm{ml}$ of PBS was injected into the uterine tubes or uterine cavity, respectively.

Assessment of lesions and collection of specimens. Laparotomy was performed on the eight inoculated monkeys after 5-8 days, 9-14 days and 21-23 days and, in the case of monkeys 1-4, also after 5-6 months. The sexual organs were examined for gross lesions and either biopsy or swab specimens or both were collected from the uterus, uterine tubes, fimbriae, parametria, and the intestinal serosa. Vaginal swabs were taken at varying intervals from 5-8 days after inoculation until 5-6 months later.

Culturing of specimens. For recovery of $U$. urealyticum, swabs collected from the infected animals were inserted immediately into liquid S-medium (Black, 1973). After incubation at $37^{\circ} \mathrm{C}$ for $24 \mathrm{~h}$, subcultivation was made in liquid and on solid medium, i.e., S-medium supplemented with $1.1 \%$ Purified Agar (Oxoid). After incubation for $24 \mathrm{~h}$, the secondary liquid culture was further subcultivated on solid medium. All agar plates were incubated at $37^{\circ} \mathrm{C}$ in air with $10 \% \mathrm{CO}_{2}$ and were examined, under a stereomicroscope, after 3 days and again, if negative, after a further 7 days. Swabs were also cultured for bacteria, as previously described (Møller $e t$ al., 1978).

Histology. Biopsies from the uterus, uterine tubes and parametria were fixed in $10 \%(\mathrm{v} / \mathrm{v})$ formalin, embedded in paraffin and stained with hematoxylin and eosin.

Serology. Sera were examined for antibodies by the indirect haemagglutination (IHA) test, with formalinised sheep erythrocytes sensitised with ultrasonically-treated ureaplasma suspensions (Krogsgaard-Jensen, 1971).

\section{RESULTS}

All eight monkeys remained apparently healthy throughout the period of observation. There were no significant rises of rectal temperature, nor changes of erythrocyte-sedimentation rate or leucocyte counts outside the range of pre-inoculation values.

\section{Gross appearance of genital organs}

At no time was swelling or redness observed of the uterus, uterine tubes, ovaries or parametria, nor was there any exudate or pus in the lumen of the tubes or in the cul-de-sac. Cysts were not seen.

\section{Histology}

Biopsies taken from the uterus, uterine tubes and parametria showed no signs of inflammation, except for occasional slight hyperaemia of the tubal mucosa and, sometimes, slight infiltration of the parametria with mononuclear cells. There was no fat necrosis or formation of granulation tissue. The lumen of the fallopian tubes was invariably normal, without exudate or inflammatory cells.

\section{Recovery of mycoplasmas}

Monkeys 1 and 2, given injections of pools of freshly-isolated human strains of $U$. urealyticum into the uterine tubes, yielded growths of ureaplasmas, from the tubes or from the 
fimbriae or from both sites, on days 5-14. Organisms could still be recovered from the vagina of monkey 1 five months later, but were present in the vagina of monkey 2 for only 1 week. From monkey 3 , given an injection of the reference strains, serotypes I-VIII, into the uterine tubes, ureaplasmas were grown from the uterine tubes at 5-14 days and from the vagina after 5 months. Monkey 6, given a mixture of freshly isolated human strains of serotypes III, IV and VIII, yielded ureaplasmas from the vagina on day 5 , but not later. Ureaplasmas could not be grown from monkey 4, challenged with freshly isolated simian strains of serotypes VI and VIII into the uterine tubes, nor from monkey 5 , given the serotype $\mathrm{V}$ reference strain into the uterine cavity. No attempt was made to serotype the various isolates. Both control monkeys remained persistently negative for growth of ureaplasmas.

Apart from the isolation of Staphylococcus aureus and Pseudomonas sp. on two occasions from the intestinal serosa of monkey 5 , bacteria were not isolated in significant numbers.

\section{Serology}

Specific IHA antibodies could not be demonstrated against any of the eight $U$. urealyticum serotypes in any of the monkeys throughout the observation period.

\section{Discussion}

Although we were able earlier to produce salpingitis in grivet monkeys by the experimental inoculation of $M$. hominis (Møller et al., 1978; Møller and Freundt, 1979; Møller, 1981), M. fermentans (Møller et al., 1980), or C. trachomatis (Ripa et al., 1979; Møller and Mårdh, 1980), 1980 ), our present attempts to do so with $U$. urealyticum were unsuccessful.

This does not necessarily imply that $U$. urealyticum is non-pathogenic for other non-human primates or for man. Thus, Bowie et al. (1978) demonstrated transient colonisation of the urethra of male Macaca fascicularis monkeys by two strains of $U$. urealyticum, after experimental inoculation, associated in some cases with increased numbers of polymorphonuclear leucocytes.

In the present tests, the eight serotypes of $U$. urealyticum were capable of colonising the genital mucosae for varying periods of time, but failed to produce inflammatory genital disease or any serological response. This probably indicates a real resistance of grivet monkeys to infection with $U$. urealyticum because, in the same experimental conditions, they are highly susceptible to infection with M. hominis (Møller et al., 1978, Møller and Freundt, 1979; Møller, 1981), M. fermentans (Møller et al., 1980) and C. trachomatis (Ripa et al., 1979; Møller and Mårdh, 1980).

In man, $U$. urealyticum is a very frequent inhabitant of the mucosa of the lower genito-urinary tract (Taylor-Robinson and McCormack, 1979). It was isolated in pure culture from samples collected through the laparoscope from the uterine tubes of two out of 52 cases of salpingitis studied by Mårdh and Westrom (1970). Another report described its isolation, in the absence of other micro-organisms, from a tubo-ovarian abscess (Braun and Besdine, 1973). However, we are not aware of any serological investigations for antibodies against $U$. urealyticum in patients with salpingitis. Urethritis has also been produced experimentally in two volunteers by inoculation of two strains of $U$. urealyticum serotype $\mathrm{V}$ (Taylor-Robinson $e t$ al., 1977), although the same strains failed to produce urethritis in three male chimpanzees even after previous passage of the strains for 14 days or more in chimpanzees (Taylor-Robinson et al., 1978)

More studies are required to confirm the pathogenicity or otherwise of $U$. urealyticum in man and monkeys.

This work was supported by grants from the Danish Medical Research Council and Aarhus Oliefabrik. 


\section{REFERENCES}

BLACK, F. T. 1970. Serological methods for classification of human T-mycoplasmas. In Proceedings of Fifth International Congress of Infectious Diseases, edited by K. H. Spitzy and H. Radl, Verlag der Wiener Medizinischer Akademie, Vienna, 1, 407.

BLACK, F. T. 1973. Modifications of the growth inhibition test and its application to human T-mycoplasmas. Appl. Microbiol., 25, 528.

BlACK, F. T. 1974. Human T-mycoplasmas (Ureaplasma urealyticum). Ph.D thesis, University of Aarhus.

Bowie, W. R., Digiacomo, R. F., Holmes, K. K. and Gale, J. L. 1978. Genital inoculation of male Macaca fascicularis with Neisseria gonorrhoeae and Ureaplasma urealyticum. Br.J. vener. Dis., 54, 235.

BRAUN, P. AND BESDINE, R. 1973. Tuboovarian abscess with recovery of T-mycoplasma. Amer. J. Obstet. Gynaec., 117, 861.

KROGSGAARD-JENSEN, A. 1971. Indirect hemagglutination with Mycoplasma antigens: effects of $p \mathrm{H}$ on antigen sensitization of tanned fresh and formalinized sheep erythrocytes. Appl. Microbiol., 22, 756.

MÅRDH, P.-A. AND WESTRÖM, L. 1970. Tubal and cervical cultures in acute salpingitis with special reference to Mycoplasma hominis and T-strain mycoplasma. Br.J. vener. Dis., 46, 179.

MølleR, B. R. 1979. Technical modification of the method for direct and indirect immunofluorescence of unfixed mycoplasma colonies. J. appl. Bact., 46, 185.

MølleR, B. R. 1981. Comparison of serological tests for detection of Mycoplasma hominis antibodies in female grivet monkeys with experimentally induced salpingitis. Acta path. microbiol. scand. sect. B., 87, 9.

MølleR, B. E. AND FREUNDT, E. A. 1979. Experimental infection of the genital tract of female grivet monkeys by Mycoplasma hominis: effects of different routes of infection. Infect. Immun., 26, 1123.

Møller, B. R., Freundt, E. A., Black, F. T. and Frederiksen, P. 1978. Experimental infection of the genital tract of female grivet monkeys by Mycoplasma hominis. Infect. Immun., 20, 248.

Møller, B. R., Freundt, E. A., Black, F. T. and Melsen, F. 1980. Experimental infection of the upper genital tract of female grivet monkeys with Mycoplasma fermentans. J. med. Microbiol., 13, 145.

MølLER, B. R., AND MÅRDH, P.-A. 1980. Experimental salpingitis in grivet monkeys. Modes of spread of infection to the fallopian tubes. Acta path. microbiol. scand., sect. B, 88, 107.

Ripa, K. T., Møller, B. R., MÅrdh, P.-A., Freundt, E. A. AND MelSEn, F. 1979. Experimental acute salpingitis in grivet monkeys provoked by Chlamydia trachomatis. Acta path. microbiol. scand., sect. B, 87, 65 .

Taylor-Robinson, D., Csonka, G. W. and Prentice, M. J. 1977. Human intra-urethral inoculation of ureaplasmas. $Q . J l M e d .$, new. ser., 46, 309.

TAYLOR-RoBINSON, D. AND MCCORMACK, W. M. 1979. Mycoplasma in human genito-urinary infections. In The mycoplasmas, vol. 2, edited by J. G. Tully and R. F. Whitcomb, Academic Press, New York \& London, p. 307.

Taylor-Robinson, D., Purcell, R. H., London, W. T. and Sly, D. L. 1978. Urethral infection of chimpanzees by Ureaplasma urealyticum. J. med. Microbiol., 11, 197. 